\title{
Survey of Flight Instructors’ Experiences in Communication Training
}

\author{
Julie C. Hall \\ University of North Dakota
}

\begin{abstract}
A self-report survey of flight instructors $(\mathrm{N}=102)$ at an upper Midwestern university flight program was administered to gather flight instructors' reflections of their experiences in communication training. Four open-ended questions yielded information about courses or training in communication flight instructors received, experiences that helped improve their ability to communicate effectively, training in effective communication with students, and participation in crew resource management courses. Content analysis methods were used to analyze data. Instructors reported experience flight instructing, coursework, their flight instructors, FAA materials, and daily life interactions as sources of training and experience in communication. Training implications and areas for further research are discussed.
\end{abstract}

\section{INTRODUCTION}

A flight instructor's work is built on the ability to communicate. Flight instructors communicate verbally and nonverbally with their students, teaching the knowledge, skills, and attitudes needed to be a successful pilot (Federal Aviation Administration [FAA], 2008). Flight instructors impact the ultimate success of a student. The FAA's Practical Test Standards (PTS) for initial flight instructor applicants (FAA, 2009) require flight instructor applicants to demonstrate the ability to effectively communicate. As official guidance to meet the standards in the PTS, the FAA Aviation Instructor's Handbook contains ten pages covering the following topics: basic elements of communication, barriers to effective communication, and developing communication skills (FAA, 2008). Even though the FAA officially dedicates only ten reference pages specifically to the topic of effective communication for flight instructors, the ability to clearly and effectively communicate permeates all areas of competency that a flight instructor applicant is required to satisfactorily demonstrate on a practical test (FAA, 2008; FAA, 2009).

Prior to this study, the author spent some time observing flight instructors with varying levels of experience and gathered some anecdotal evidence indicating that communication patterns seemed to change when a flight instructor had more flight instruction experience. This preliminary finding prompted the author to research the topic further. The author sought studies specifically dealing with communication theoretical frameworks and flight instruction. There is a large amount of work specifically addressing communication in classroom settings (e.g., McCroskey, L. L., Richmond, \& McCroskey, J. C., 2002; Rubin, 2002) as well as studies of communication in multiple flight crewmember settings (e.g., Salas, Burke, Bowers, \& Wilson, 2001; Salas, Wilson, Burke, \& Wightman, 2006). Studies of communication in flight instruction settings proved more difficult to locate. The purpose of this survey is to provide an overview of how flight instructors perceive they learned to communicate effectively in a structured collegiate flight training environment. This survey was conducted as part of a larger study and intended to be used to guide areas of future research.

In order to better understand flight instructors' perceptions of their communication training, the following research questions were addressed in this study:

1. What kind of communication training does a typical flight instructor receive when completing a degree curriculum at one highly structured collegiate flight program?

2. Do experiences shape a flight instructor's ability to communicate?

3. When obtaining their flight instructor certificate, what training did flight instructors receive specifically geared toward communicating with students? 


\section{Have flight instructors received CRM training?}

\section{METHOD}

\section{Participants}

The target population of this study is certificated flight instructors at a structured collegiate flight training program. At the time of the survey approximately 300 flight instructor certificate holders were either employed at or students of an upper Midwestern university. A total of 102 individuals volunteered to take the study survey. The flight instructors who responded to the survey reported a range of flight experience as a flight instructor between zero hours and 6,000 hours of experience.

The FAA outlines its minimum requirements for the training of flight instructors, and variance exists from school to school as to what and how flight instructors are taught. By sampling from one location, the potential for confounding the study by introducing the variable of varied learning experiences was reduced. Admittedly, the study design limits the generalizability to the university where the survey was administered.

Of the 102 respondents, 98 survey respondents indicated that they had obtained all of their flight instructor certificates at the upper Midwestern university, three survey respondents indicated that they had obtained some of their flight instructor certificates at the university, and one respondent indicated that they had obtained all flight instructor certificates at places other than the university. In order to be eligible to take the university's course to become a flight instructor, students must have completed at least four semesters worth of prerequisite flight courses as well as the prerequisites and corequisites for the flight courses (University of North Dakota [UND], 2011a; UND, 2011b). Examples of the non-flight related required courses are: meteorology, aviation safety, and aircraft systems. Since 98 of the survey respondents indicated that they had obtained all of their flight instructor certificates at the upper Midwestern university, an overwhelming majority of the sample was subjected to similar training experiences over a period of years.

The university has a FAA-certificated Part 141 training program (Federal Aviation Regulations, 2009), it is accredited by the Aviation Accreditation Board International (AABI) (Aviation Accreditation Board International [AABI], 2010), and it is a University Aviation Association (UAA) member (University Aviation Association [UAA], 2011). In addition to the flight instructor course that includes practice instruction experiences, the college curriculum for a bachelor's degree with a major in commercial aviation at the university includes required coursework in public speaking, writing, Crew Resource Management (CRM), and a flight course in the Canadair Regional Jet (CRJ) simulator that requires crew interaction. This commercial aviation degree curriculum is well above and beyond basic FAA requirements to obtain a flight instructor certificate (FAA, 2009).

The exact dates that the survey respondents obtained their training at the university was not asked on the survey, but can be inferred from the range of flight experience reported. Some variance in training experiences may exist due to slight changes that were made to the university's curriculum over the years. To illustrate the magnitude of changes made to curricula, since 2001 the following changes were made to the commercial aviation major curriculum at the university: added and deleted a requirement for an interpersonal communication course, added and deleted an information technology course, replaced a course in air transportation with a senior capstone, and added the choice between courses in creative writing, writing non fiction, and business communication rather than requiring the business communication course (UND, 2011a; UND, 2011b). It can be assumed that the sample was subjected to a similar level of structure, rigor, and enhanced curriculum available at an FAA-certificated Part 141, AABI-accredited, UAA-member program. 


\section{Procedures and Instrument}

An anonymous self-report survey was used to collect data. The first section of the survey consisted of several closed questions regarding gender, total flight experience in hours, total flight instruction experience in hours, instructor certificates held, whether or not all flight instructor certification training was obtained at the university, and the quantity of experience obtained as a crewmember in an aircraft requiring more than one flight crewmember. The four open-ended questions in the survey used to gather qualitative data were:

1. Please describe courses or training in communication you have received.

2. What experiences do you believe helped improve your ability to communicate effectively?

3. In your training for the first flight instructor certificate you obtained, what training did you receive on communicating effectively with your students?

4. Have you participated in any crew resource management (CRM) courses? Please describe. Do you think that CRM courses are helpful and worthwhile, or is CRM something you learn more by doing?

Before launching, the survey was reviewed for clarity, ease of response, and validity by four experts including two professional pilots and two professors well-versed in research methods. In compliance with Institutional Review Board (IRB) approved procedures, study advertisements were made via mass email and poster-sized signs posted in high-traffic areas during the week of data collection.

The survey was administered over the period of one week, Monday through Friday, from 9:00 AM to 7:00 PM in a university computer lab. When survey participants arrived at the computer lab to participate in the survey, they were given an IRB-approved information sheet to review. After reading the information sheet conditions and agreeing to them, each was given a paper copy of the survey and shown to a cubicle to complete the survey. The survey took approximately 20 minutes to complete and all survey participants were compensated $\$ 5.00$ for their time. The $\$ 5.00$ amount was mentioned in all advertisements and given to all participants regardless of how much of the survey they completed. Survey forms were disseminated, collected, and stored by the principal investigator according to approved procedures.

Content analysis methods were employed to analyze the qualitative data obtained on each of the four questions. The same framework for analysis was employed on each question individually. Responses were read by the principal investigator, and the words written by respondents for ideas and concepts in responses were recorded in theme clusters. All participants responded to each of the four questions, and content from the responses revealed common themes. Theme clusters were developed based upon the data from the responses received and vary from question to question. The number of responses in each cluster was also noted to determine the cluster with the largest number of responses to each question. Due to the ability of a respondent to indicate multiple responses on a single question that fall into multiple independent theme cluster groups, some of the proportions of responses to a question add up to more than $100 \%$.

\section{Limitations}

The limitations associated with qualitative research, content analysis methods, and self-report survey methods apply to this survey. Some of the possible limitations are: the inability to read some of the respondents' handwriting, the possibility of creating a coding scheme that has too many or too few theme clusters, and the possibility of misinterpretation. All respondents to this survey were employees or students of a single university, and as such, their responses may only apply to the affiliated university. Survey participants volunteered to participate, and their participation may be influenced by things such as 
individual interpretation of the open-ended questions, individual interpretation of the terms used in the questions, biases, and the desire to respond in a socially acceptable manner.

\section{RESULTS}

\section{Question 1: Courses and Training in Communication}

The first open-ended question on the survey was, "Please describe courses or training in communication you have received.” Ninety eight of 102 participants responded to this question by stating aviation-specific and general education courses at the Midwestern university, and the remaining four respondents did not include any university coursework in their responses. The university courses mentioned included: Aviation Safety, CRM, Advanced Aircraft Operations/CRJ course, Flight Instructor courses including Certified Flight Instructor (CFI), Instrument Flight Instructor (CFII) and Multi-engine Flight Instructor (MEI), Human Factors, Business Communication, Public Speaking, and Interpersonal Communication. A few respondents elaborated that the group work required in upper-level courses contributed, and that all flight courses included elements of learning how to communicate with others. Other university coursework viewed as beneficial were foreign language courses and psychology courses. In addition to university coursework, a few other themed responses were made in response to Question 1 by five or fewer respondents each: aviation training outside the university, leadership courses and seminars, employer courses, high school, and working with others.

\section{Question 2: Communication Experiences}

The second open-ended question on the survey asked, "What experiences do you believe helped improve your ability to communicate effectively?” The largest groups of responses are displayed in Figure 1.

Figure 1. Question 2 Responses

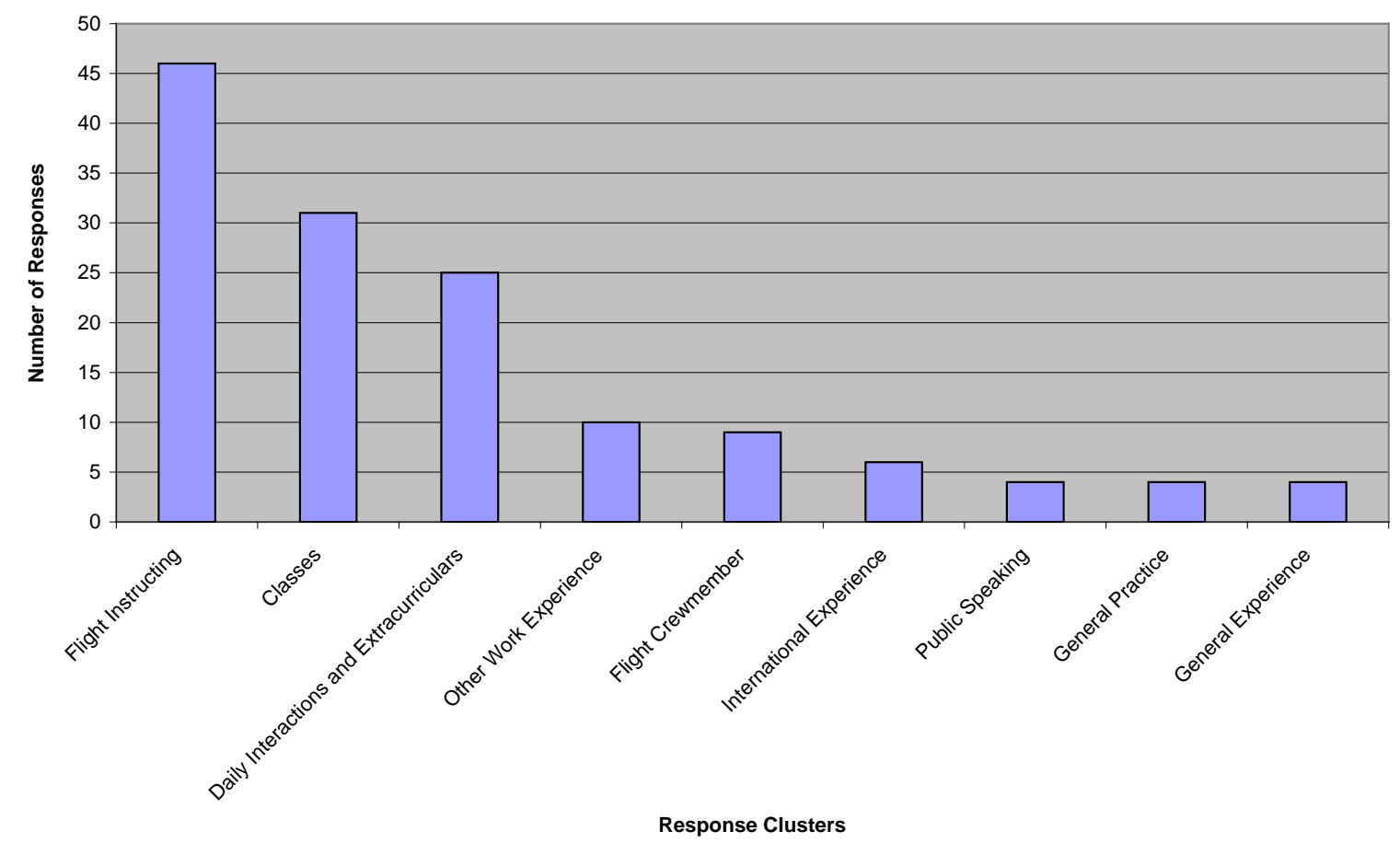

Figure 1: Question 2 Responses 
A few additional responses that did not fit into groupings were: observing communication in a cockpit jump seat, self study by reading books, leadership training, the university's standardization of communication, and the idea that personality is the factor that makes people more or less expressive.

Forty-six of the survey responses made reference to experience flight instructing as an experience that improved their ability to communicate effectively. Some respondents elaborated that they gained comfort and confidence through their experiences. Some mentioned interactions with air traffic control and radio communications. A few mentioned the high-stress environment and one expressed the need to be patient while instructing. Also mentioned were the interactions with different levels and types of students as well as interactions with other flight instructors. One expressed that flying with a low time pilot forces clear and effective communication. While coursework may have helped these survey respondents get off to a start, the group of individuals who responded that flight instruction was helpful had some quotes that illustrate their views on gaining actual experience: "Working with students on a day to day basis helps a lot, sort of a sink or swim method of learning," and, "Actually flight instructing for the first time was the best experience for effectively communicating with students. Even though a flight instructor attempts to act like a student, it is no substitute for actually teaching someone.” Thirty-one respondents indicated that their classes including aviation and communication coursework helped them. In particular, coursework in CRM and CRM related topics were mentioned in response to this question, as well as the CRJ course. Students in the CRJ course are required to complete simulator sessions as part of a flight crew.

Twenty-five of the respondents indicated that daily life social interactions and extracurricular activities enhanced their ability to communicate. As an example of daily social interactions, three people specifically mentioned living with people or having roommates as experiences that have shaped their ability to communicate. Social interactions, participation in clubs and social functions, and playing sports were all mentioned. A few people mentioned conversing with friends who have different communication styles and defending ideas in group settings. One mentioned that being social throughout their life shaped their ability to communicate, and another added that practice communicating in a diverse population at home helped. One elaborated that talking with others about misunderstandings or miscommunications was helpful. One respondent remarked the following views on everyday communication: "Experiences in leadership outside of school in clubs and the (organization name) have better prepared me to communicate than any class. It is hard to teach someone to relate to people.”

International experiences included both international travel and working with international flight students, which some noted was an experience that helped improve their ability to communicate clearly. Some mentioned the experience working as a member of a flight crew was beneficial, and for purposes of this analysis, that interaction experience is grouped with working as a flight crewmember in the training environment since references were made to the actual flight practice in the CRJ simulator. Ten of the respondents indicated that work experiences in jobs outside of aviation were beneficial. Those who responded with information about their jobs indicated that they interacted often with people, such as sales and refereeing sports, or worked in team environments such as being in the military.

The following response clusters were mentioned by four respondents each as things that enhanced their ability to communicate: additional opportunities to engage in public speaking, practice in general was helpful, and experience in general. There were additional responses that did not fit neatly into the groupings. The responses included: observing communication in a cockpit jump seat, self study by reading books, leadership training, the university's standardization of communication, and personality.

\section{Question 3: Flight Instructor Communication Training}

The third open-ended question posed on the survey was, "In your training for the first flight instructor certificate you obtained, what training did you receive on communicating effectively with your students?” Responses to this question tended to fall into one of two overarching categories: responses that centered 
on the method of delivery of the training received, and responses that centered on the content of the training received. Figure 2 illustrates the groupings of responses that were clustered according to the method or delivery of communication training.

Figure 2. Question 3 Method or Delivery Responses

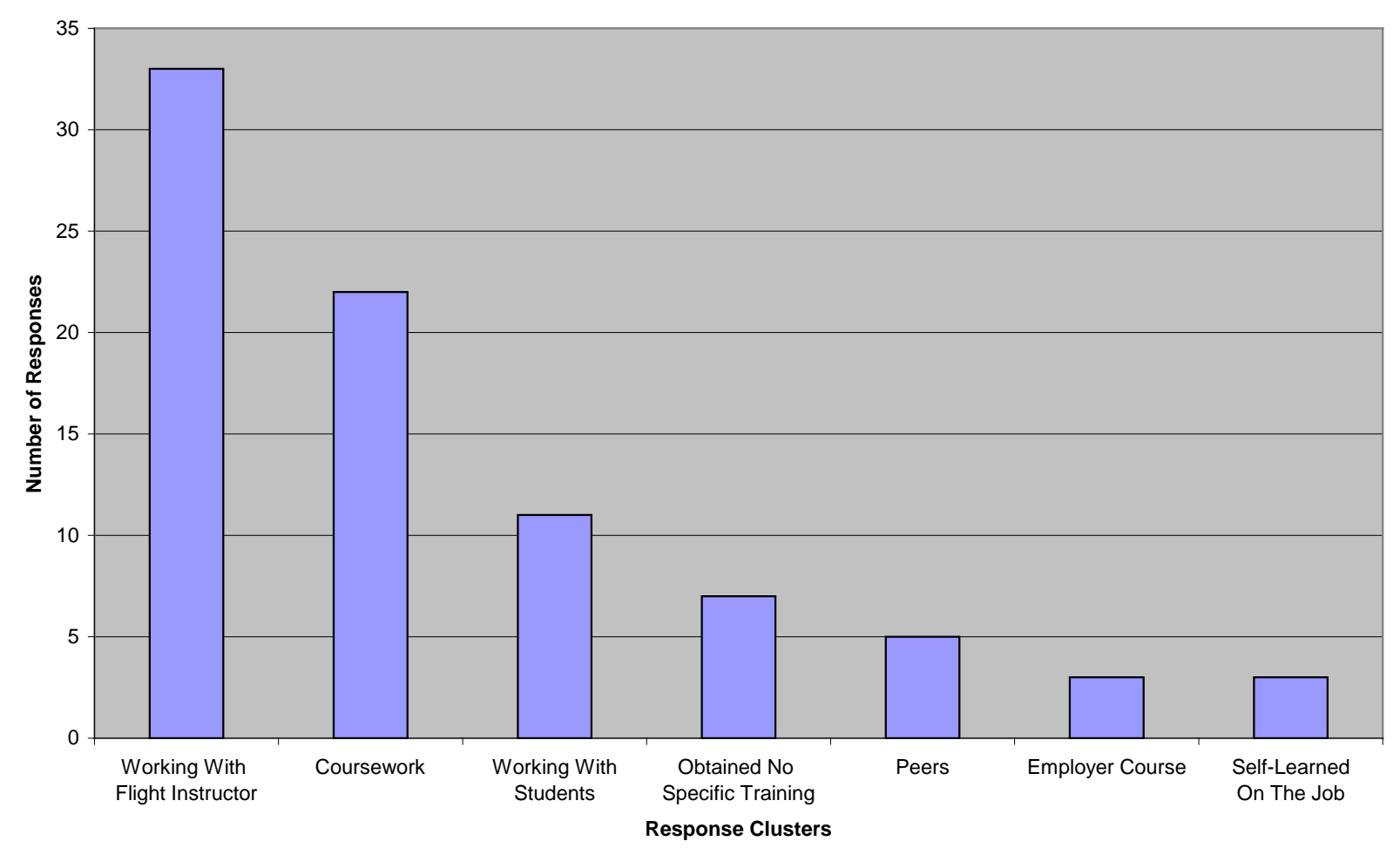

Figure 2. Question 3 Method or Delivery Responses

In terms of the content of training, the main response was either the Aviation Instructor's Handbook published by the FAA (2008) or the fundamentals of instruction (FOI) material contained inside that publication. Responses indicating the university CFI course and other courses such as CRM were counted in the overarching group as methods of delivery, but have also been considered in the content category as many of the responses did not elaborate on the content beyond listing their participation in the courses. University courses are assumed to have content as each course has a syllabus outlining its content. Due to the content of the input that flight instructors provide during a typical flight lesson involving practice flight or practice ground instruction, working with a flight instructor was not only considered in the overarching group as a method of training delivery, but also in the training content group. The types of responses clustered as content when working with a flight instructor included responses such as the instructor acting like a student and instructor’s feedback. See Figure 3 for responses regarding content. 
Figure 3. Question 3 Content Responses

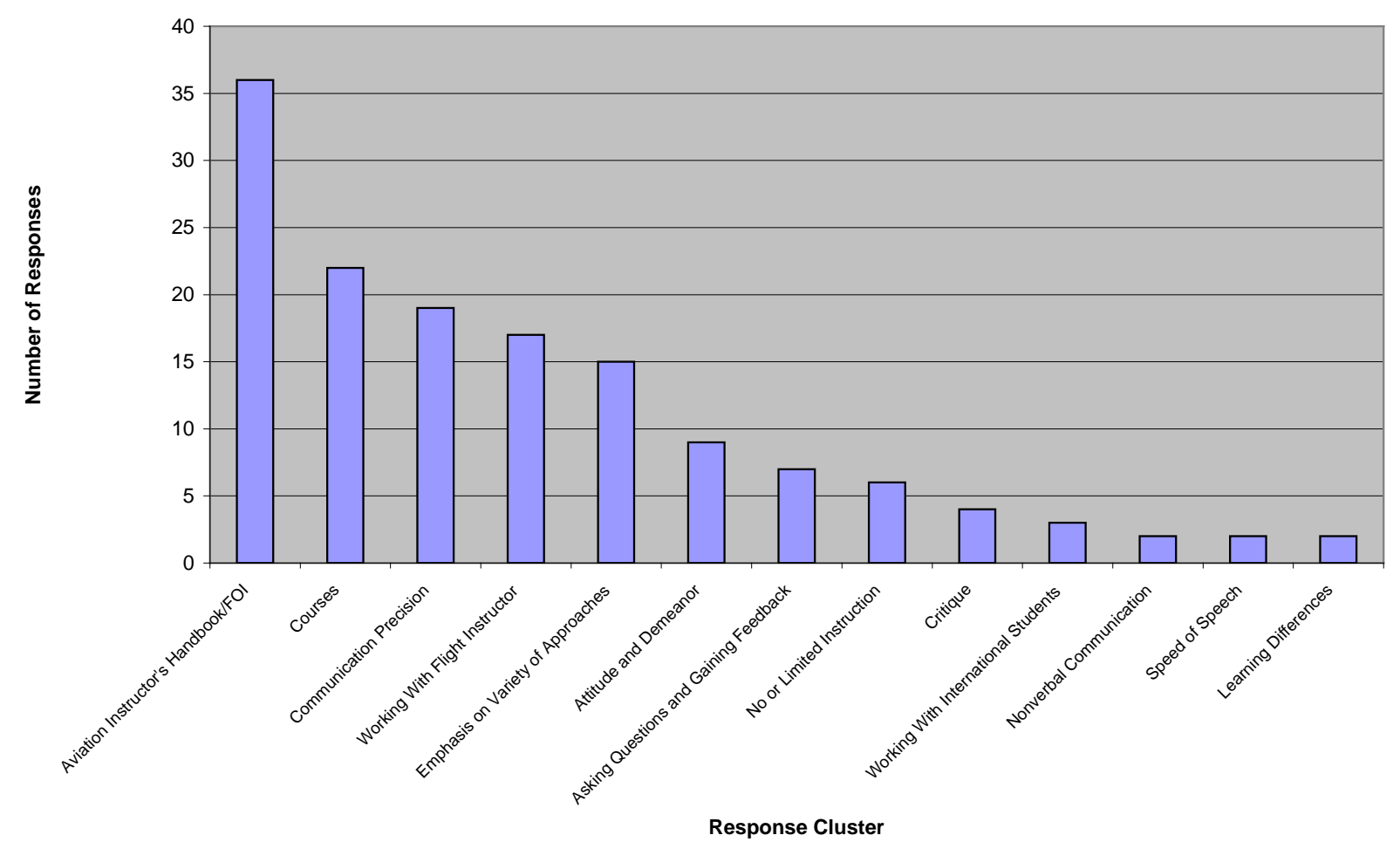

Figure 3. Question 3 Content Responses

Other ideas that received mention regarding training content were: FAA publications, books, conflict, visual communication, barriers to communication, preparation for lessons, and defensive positioning. When this question is viewed in combined terms of delivery and content, the two most popular answers were applicants working with their flight instructors, and the FAA's publication the Aviation Instructor's Handbook (2008). While the FAA's Aviation Instructor's Handbook (2008) is a publication with a finite, defined body of content delivered to all who read it in a uniform manner, flight instructors differ with regard to the content and delivery of material taught. The following quotations from survey respondents illustrate some of this variance in communication instruction and feedback given by flight instructors to their flight instructor applicant students:

"Instructor attempted to be a difficult student, essentially not understanding things. Making me try different ways of teaching/comm. Otherwise it was based on instructors' thoughts on how I did.”

“Extremely little. Periodically my CFI instructor would 'feign' disinterest in order to force me to directly engage her with the briefing."

"When I first started CFI, I used advanced aviation terms. My instructor simply said, 'I don't know ANYTHING about airplanes/flying. What is that?' It helped me to be more careful in word choices.”

"Very little, I received much more training from my CFII flight instructor. He taught me to be precise and assertive, and I learned to judge the feedback the student is giving." 
"My flight instructor emphasized the need to get feedback from a student to know they really understand a concept. Also that it is important to teach something correctly the first time. The FOI communication chapter was also taught.”

"The F.O.I. provides some tips on dealing with students and learning styles, but much of it seems very simplistic. The best resource is simply prior instructors who were either good or bad, and using that as a guide.”

\section{Question 4: CRM Opinions}

The final open-ended question posed on the survey was, "Have you participated in any crew resource management (CRM) courses? Please describe. Do you think that CRM courses are helpful and worthwhile, or is CRM something you learn more by doing?” The most popular answer theme, with 48 respondents, was that they took a CRM course at the university, the CRM course was beneficial in providing a foundation of learning, and that CRM is something that must be further learned by doing after gaining the foundation. Another 35 respondents indicated that they had taken a CRM course at the university and found it beneficial. See Figure 4 for responses to Question 4.

Figure 4. Question 4 Responses

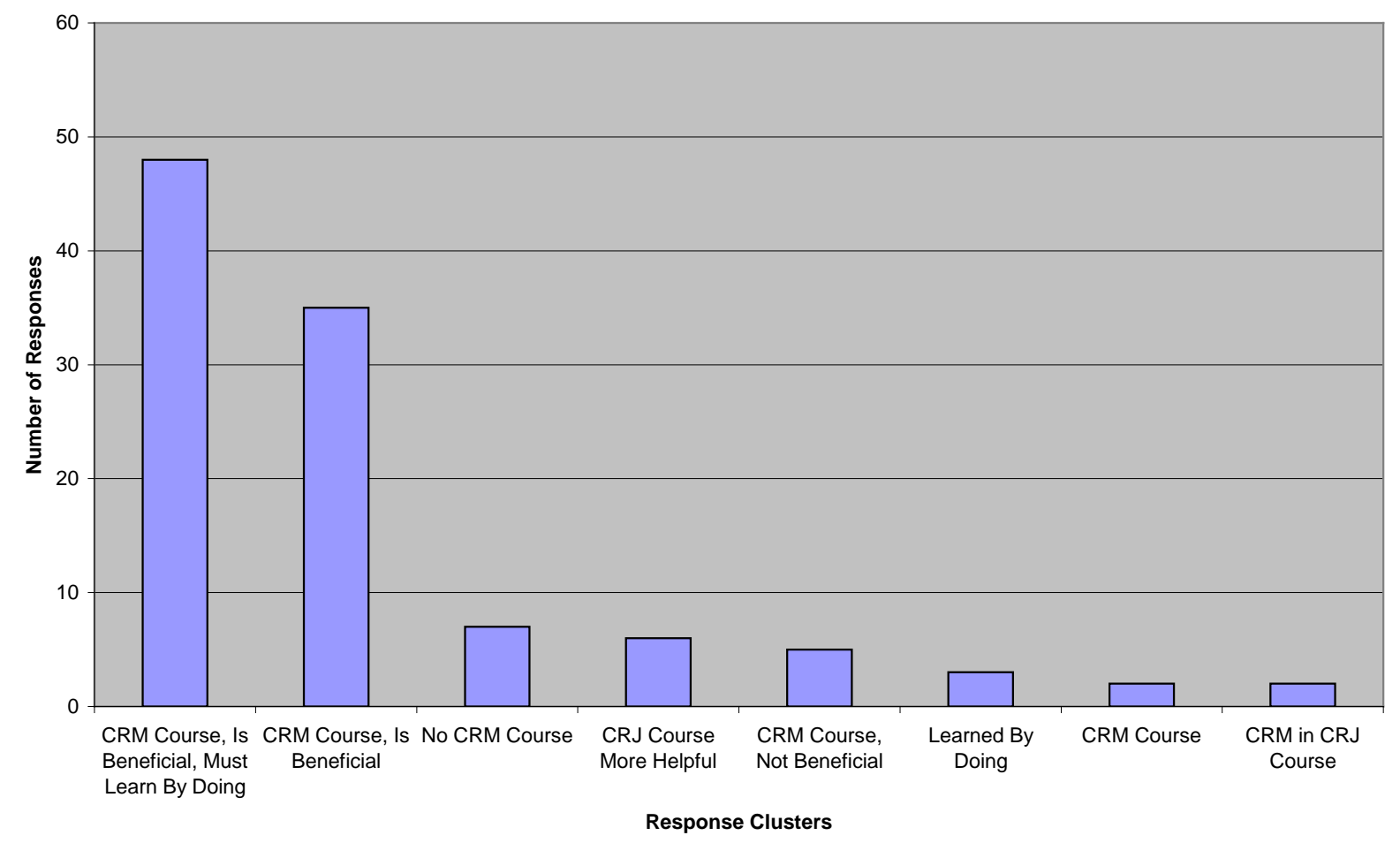

Figure 4. Question 4 Responses

There was much discussion about CRM in the context of multiple-crewmember settings from survey respondents, but very little mention of flight instruction in responses to this question. Two respondents specifically mentioned that CRM courses did not address flight instructor/student dyadic interactions. Other comments made in response to this question were that the instructor is important in the success of a CRM course, and that observing flight crews was beneficial. 


\section{DISCUSSION}

When examined as a whole, the grouped responses to the questions reveal some patterns and spark new questions. The top three grouped responses to Question 2 regarding experiences that helped improve the ability to communicate were: experience flight instructing, classes, and daily life interactions and extracurricular activities. It is not entirely surprising that experience flight instructing was the top answer to Question 2 as every respondent in this sample is a certificated flight instructor. What remains unanswered is the following question: What are flight instructors learning by actually instructing? It is possible that the answer to this question includes concepts that are not currently included in formal coursework or published FAA materials. The third most frequent response group was daily life interactions and extracurricular involvement, indicating that social activities can have an impact on a person’s ability to communicate in a variety of settings, including professional settings.

Question 1 asked specifically about courses or training, and Question 2 asked about experiences. Even though Question 2 asked specifically about experiences, one third of the respondents still mentioned their university courses as experiences that helped their ability to communicate. Collegiate aviation programs need to be mindful of students' reliance on the curriculum and build a curriculum that addresses the need for both general interpersonal communication skills and specialized aviation communication skills. Ideally, students should possess a solid foundation of basic interpersonal communication skills early in their college career. Once a solid foundation of interpersonal communication competence is built, specialized CRM communication and flight instructor communication skills can be addressed in upper division courses.

The responses to Question 3's inquiry about the training received in communicating effectively with students make it clear that the FAA's publications, especially the content considered the fundamentals of instruction in the Aviation Instructor's Handbook (FAA, 2008) are the basis of much of what this group of flight instructors considered regarding communication during their training to become a flight instructor. Flight instructors were also regarded as important sources of information as many responded that ideas and feedback provided by instructors comprised much of what was learned about instructional communication. While great value was placed on what flight instructors had to say about instructional communication, it is difficult to effectively define what knowledge flight instructors are bestowing upon students beyond some smaller idea clusters and some of the quotations shared. The material in the FAA's publication is defined; the material passed on by flight instructors is not and varies. What communication skills are flight instructor applicants learning from their instructors? It is possible that the material flight instructors cover with their students includes aspects of interpersonal communication competence or instructional communication techniques that are more detailed than addressed by coursework or the FAA's published materials.

Several other ideas of content regarding interpersonal communication were shared by survey respondents in response to Question 3, though it is not entirely clear whether those ideas originated from flight instructors or FAA publications. Another observation of the specific communication concepts mentioned in content-related responses to Question 3 is that a larger number of survey respondents indicated that material regarding communication delivery (e.g. communication precision, attitude projection) was covered than the number of survey respondents indicating that responsiveness behaviors (e.g. listening to student, interpreting student feedback) were covered. It is possible that the responsive communication behaviors are some of the more subtle behaviors that flight instructors learn through experience.

Flight instruction is only mentioned in a few instances in responses to Question 4's question about participation in CRM courses. There was minimal overlap of mentions of flight instruction with CRM, 
possibly illustrating that respondents compartmentalized CRM separately from flight instruction communication.

\section{Future Directions}

Much research is yet to be done that could benefit the communication training of flight instructors. Two of the important questions yet to be better answered were mentioned above. What are flight instructors learning by actually instructing? Also, what communication skills are flight instructor applicants learning from their instructors? A greater understanding of the content of the material being verbally passed from one generation of flight instructor to the next generation through one-on-one training interactions would help to define useful concepts that are being perpetuated outside of the FAA's required materials. Since so many respondents indicated that they learned by actually flight instructing, an examination of the differences in communication skills between a newly certificated flight instructor and a highly experienced flight instructor would help define what beneficial communication skills are learned through flight instruction experience. Having a more detailed, defined set of instructional communication skills beneficial for flight instructors could help develop more comprehensive curricula and training materials for flight instructor applicants in pursuit of a flight instructor certificate. More importantly, newly certificated flight instructors might be more comprehensively equipped to communicate with their first students.

Beyond learning through actual flight instruction, a large number of survey respondents indicated reliance on coursework for training in effective communication. Currently, entire courses are devoted solely to CRM, while communication concepts useful to a flight instructor are sprinkled within the ground school and flying portions of a flight instructor course. While some CRM concepts may be useful in flight instruction settings, assuming that a CRM course helps arm a flight instructor for their position would be difficult since CRM communication concepts and flight instruction communication concepts involve two different dyadic relationships.

An audit of a curriculum, including the communication concepts addressed in individual courses, could be beneficial in building a comprehensive communication skills curriculum that better equips future aviation professionals for the subtleties of different types of interpersonal communication. It cannot be assumed that all incoming college students will possess the baseline interpersonal communication skills upon which to build CRM communication and flight instruction communication skills. A communication skills exam upon entrance to a college program, similar to a math placement exam, could serve as a tool to identify a student's shortcomings in communication skills. Development of such an exam could be directed by skills identified as important, and early general education requirements could fill potential gaps and solidify a student's communication skills foundation.

Studying interpersonal communication in flight instruction and strengthening interpersonal communication curricula may seem like daunting tasks as much work would be required to gain clear insights into the questions raised above. Scholarship in communication and based on communication theoretical frameworks offers ideas and instruments that could possibly be beneficial in studying communication in flight instruction. For example, theories centered on interpersonal communication and some of the instruments developed by McCroskey and Richmond (1996), such as the SocioCommunicative Orientation Scale (SCO) and the SocioCommunicative Style Scale (SCS), could be useful (Richmond \& McCroskey, 1990). Dozens more communication theoretical frameworks and instruments exist that could be useful in studying communication in flight instruction settings. Interpersonal communication curricula could also be strengthened with the theoretical frameworks and curricula that have been forwarded by communication scholarship. Morreale and Backlund (2002) provide an overview of the concepts in communication curricula scholarship. Communication in flight instruction could be strengthened by appropriate integration of communication scholarship in aviation. 
Many survey respondents indicated that everyday interactions and involvement in extracurricular activities were beneficial in shaping their ability to communicate with others. Aviation students no doubt spend a large amount of time flying, attending class, and studying. It is possible that a typical student's college interpersonal relationship experiences have been altered by the prevalence of electronic communication such as internet social media and text messaging. A survey of aviation students to determine whether they are involved in at least one extracurricular or work activity, to determine what other demands are placed on their time, and to determine typical communication patterns could illustrate what a typical student is exposed to in terms of opportunity to learn to communicate through practice interacting. It is true that an aviation student's involvement in intramural sports may not have a direct correlation with how well they can fly an instrument approach, but it may serve as a nonthreatening method of helping a typical student learn how to be a leader, a follower, or merely play well with others in a cockpit. 


\section{REFERENCES}

Aviation Accreditation Board International. (2010). Aviation Accreditation Board International. Retrieved November 10, 2010, from http://www.aabi.aero

Federal Aviation Administration. (2008). Aviation instructor's handbook. (FAA-H-8083-9A). Washington, DC: U.S. Department of Transportation, Federal Aviation Administration.

Federal Aviation Administration. (2009, March 16). Flight instructor practical test standards (FAA-S-8081-6C, Changes 1, 2, 3, 4). Washington, DC: U.S. Department of Transportation, Federal Aviation Administration Flight Standards Office.

Federal Aviation Regulations, 14 C.F.R. § 141 (2009).

McCroskey, J. C., \& Richmond, V. P. (1996). Fundamentals of human communication. Prospect Heights, IL: Waveland Press, Inc.

McCroskey, L. L., Richmond, V. P., \& McCroskey, J. C. (2002). The scholarship of teaching and learning: Contributions from the discipline of communication. Communication Education, 51, 383-391.

Morreale, S. P., \& Backlund, P. M. (2002). Communication curricula: History, recommendations, resources. Communication Education, 51, 2-18.

Richmond, V. P., \& McCroskey, J. C. (1990). Reliability and separation of factors on the assertivenessresponsiveness scale. Psychological Reports, 67, 449-450.

Rubin, L. E. (2002). Binocular vision for communication education. Communication Education, 51, 412419.

Salas, E., Burke, C. S., Bowers, C.A., \& Wilson, K. A. (2001). Team training in the skies: Does crew resource management (CRM) training work? Human Factors, 43, 641-674.

Salas, E., Wilson, K. A., Burke, C. S., \& Wightman, D. C. (2006). Does crew resource management training work? An update, an extension, and some critical needs. Human Factors, 48, 392-412.

University Aviation Association. (2011). University Aviation Association. Retrieved March 18, 2011, from http://www.uaa.aero/

University of North Dakota. (2011a). Previous academic catalogs. Retrieved March 27, 2001, from http://www.und.edu/dept/registrar/catalogs/catalogs.htm

University of North Dakota. (2011b). Welcome to the 2009-2011 UND academic catalog. Retrieved March 27, 2011, from http://www.und.edu/dept/registrar/catalogs/catalog/index.htm 